\title{
Editorial
}

\section{Seguimos creciendo}

Camino a la consideración de relevancia científica que las publicaciones ofrecen, Cuadernos de Psicología del Deporte se mantiene firme y definida hacia su apuesta de canalizar conocimiento científico y transferencia a la sociedad.

Un nuevo número que permite dar explicabilidad, sin perder los criterios de calidad científica que nos han caracterizado, a conceptos que intervienen en diversos ámbitos de la práctica de la actividad física. Se reúnen en el mismo, manuscritos orientados principalmente a contextos educativos y de alto rendimiento.

Cada vez más, el deporte y la actividad física tienen un sentido funcional y transversal en la formación del individuo. Se apuesta por la práctica física y deportiva como un elemento complementario de estilos de vida saludables, de propuestas educativas y personales (adquisición de valores). Conforme las incorporamos a nuestras maneras de vida, los ajustes, los recursos, los caminos comienzan inexorablemente a individualizarse y a tornarse en numerosas cuestiones antinaturales para un desarrollo normalizado y adaptado. Es en esos momentos, donde los procesos psicológicos y personales, al mismo tiempo que su íntima relación con los recursos físico-técnicos, infieren y dan sentido de coherencia, a pesar de las resistencias o de las insistencias por lo planeado.

Todavía queda mucho conocimiento por adquirir, todavía mucho por descubrir, todavía mucho por transmitir. La realidad de lo que hacemos no es lo que ya se conoce, sino lo que a modo acumulativo incorporamos constantemente a través de la experiencia y del descubrimiento. Es aquí, donde la ciencia aporta su principal valor, y donde Cuadernos de Psicología del Deporte encuentra su razonado esfuerzo por la aportación científica.

En la sección de Psicología del Deporte, este número apuesta por la visión más formativa de los procesos psicológicos, ofreciendo el uso de herramientas educativas y aportando información sobre características estructurales de protagonistas en el deporte (deporte universitario, árbitros, triatletas, entrenadores,...), dando debida y útil información sobre la influencia en las habilidades y en los recursos de afrontamiento en cada uno de los contextos. Desde el uso de herramientas tecnológicas de última generación, a las metodologías de comunicación o a la descripción de perfiles y características básicas para la adaptación; la sección se esfuerza en señalar la medicación psicológica y mucho más explicativa en procesos aparentemente directos.

La sección de Ciencias del Deporte ofrece recursos sobre la mejora de la capacidades perceptivas y observadoras en deportistas de rendimiento (triatletas y voleibol), experiencias para desarrollar programas psicosociales y formativos en jóvenes deportistas, utilizando espacios abiertos en la naturaleza, en clubes, en centros educativos, ofreciendo las bases para un modelo de educación deportiva válido y que permita la adherencia a un estilo vital y permanente, donde la actividad física ofrezca recursos a jóvenes deportistas y profesores. Además, la interesante visión de la interpretación probabilística de la información deportiva, contempla su utilidad para la concentración en las tareas del deportista.

Estamos seguros que las oportunidades que ofrece este número para el aprendizaje de deportistas, maestros y profesores, entrenadores, padres y científicos, etc..., favorecerán ese conocimiento acumulativo, útil y con sentido de coherencia. Continuando además manteniendo unos estándares de calidad científica que permiten seguir ofreciendo y recibiendo excelentes trabajos, que tras su camino de revisión, permite que los mismos sean tenidos en cuenta, que sirvan de base a nuevas ideas y propuestas científicas, que se conviertan en referencias más allá de contextos deportivos y por encima de todo, es un orgullo para el Grupo de investigación en Psicología del Deporte de la Universidad de Murcia, que Cuadernos de Psicología del Deporte se esté convirtiendo en un vehículo de transferencia recíproca entre lo científico a lo aplicado.

Juan González Hernández

Director Cuadernos de Psicología del Deporte 